\title{
Bir İlde Ağız ve Diş Sağlığı Merkezinde Çalışan Diş Hekimlerinin illaca Bağlı Oluşan Kemik Osteonekrozu Hakkında Bilgi ve Farkındalıkları
}

\author{
Ahmet Taylan Çebiఠ
}

Karabük Üniversitesi Diş Hekimliği Fakültesi, Ağız, Diş ve Çene Cerrahisi Anabilim Dalı, Karabük, Türkiye

Ahmet Taylan Çebi, Dr. Öğr. Üyesi

İletişim:

Dr. Öğr. Üyesi Ahmet Taylan Çebi Karabük Üniversitesi Diş Hekimliği Fakültesi, Ağız, Diş ve Çene Cerrahisi Anabilim Dalı, Karabük, Türkiye

Tel: +90 37043344 01/1226

E-Posta: ahmettaylancebi@karabuk.edu.tr

Gönderilme Tarihi : 08 Kasım 2017

Revizyon Tarihi : 14 Aralık 2017

Kabul Tarihi : 17 Aralık 2017
ÖZET

Amaç: Ağız ve Diş Sağlı̆̆ı Merkezi'nde çalışan hekimlerin antirezorptif ilaçlar ve etki mekanizmaları, ilaca bağlı olarak çenelerde oluşan kemik osteonekrozu hakkında bilgi ve farkındalıklarının değerlendirilmesi amaçlanmıştır.

Hastalar ve Yöntemler: Bu çalışma, bir ilde bulunan Ağız ve Diş Sağlığı Merkezi'nde çalışan yaşları 26-55 arasında olan toplam 35 (16 kadın ve 19 erkek) diş hekiminin değerlendirilmesiyle gerçekleştirildi. Katılımclardan; sosyo-demografik ve antiresorptif ilaçlar, ilaca bağlı oluşan kemik osteonekrozu ve tedavisi konularında sorular içeren anketi doldurmaları istendi $(n=35)$. Sorulara verilen cevaplara göre farkındalık ve bilgi sahipliği düzeyleri değerlendirildi.

Bulgular: İlaca bağlı oluşan kemik osteonekrozu ve tedavisi, antiresorptif ilaçlar hakkında bilgi ve farkındalık oranı ise $\% 42,9$ olarak bulunmuştur. Toplam 35 hekimin 15 tanesi anket sorularının \%60'ına evet cevabı vererek, gerekli açıklamalarda bulunmuşlardır. Diş hekimliği ile ilgili kongrelere aktif olarak katılan ve ilgili dergileri düzenli takip eden ve özel sektörde iş tecrübesi olan, ilaca bağlı oluşan kemik osteonekrozu ve tedavisi, antiresorptif ilaçlar hakkında bilgi ve farkındalığa sahip olan kadın ve erkek hekim sayısı arasında istatistiksel olarak anlamlı bir fark bulunmamıştır $(p>0,05)$.

Sonuç: Ağız ve Diş Sağlığı Merkezi'nde çalışan diş hekimlerinin antiresorptif ilaçlar ve etki mekanizmaları, bu ilaçların neden oldukları çene osteonekrozları ve tedavileri hakkında bilgi ve farkındalık seviyelerinin düşük olduğu ortaya koyulmuştur. Daha kapsamlı ve daha geniş kitleleri içine alacak çalışmalara ihtiyaç duyulmaktadır.

Anahtar sözcükler: Çenenin bifosfonat ilişkili osteonekrozu, osteonekroz, bifosfonatlar, diş hekimleri

KNOWLEDGE AND AWARENESS OF DENTISTS WORKING AT A DENTAL HOSPITAL IN A CITY ABOUT BONE OSTEONECROSIS DUE TO MEDICATION

Purpose: This study aimed to evaluate the knowledge and awareness of dentists working at a Dental Hospital about bone osteonecrosis in jaws depending on (related to) the drugs and mechanisms of action of antiresorptive drugs.

Patients and Methods: This study was completed by evaluating a total of 35 ( 16 female and 19 male) dentists aged between 26 and 55 who worked at a Dental Hospital in a city. Participants were asked to complete a questionnaire including questions on socio-demographic and antiresorptive medications, osteonecrosis of the bone, and treatment $(\mathrm{n}=35)$. According to the answers given to the questions; the levels of awareness and information ownership were evaluated.

Results: The bone osteonecrosis related to pharmacology and treatmentin addition to the rate of knowledge and awareness of antiresorptive drugs were found as $42.9 \%$. Of the total 35 dentists, 15 responded yes to $60 \%$ of the questionnaire and provided necessary explanations. No statistically significant difference was found between the number of male and female dentists who actively participated in congresses related to dentistry and regularly followed related journals, had experience in a private sector, had knowledge and awareness about both bone osteonecrosis due to pharmacy and treatment and antiresorptive drugs $(p>0,05)$.

Conclusion: It was understood that the dentists who worked at a Dental Hospital had a low level of knowledge and awareness about antiresorptive drugs and their mechanisms of action, jaw osteonecrosis caused by these drugs and the treatments. There is a need for more extensive and broader research.

Keywords: Bisphosphonate-associated osteonecrosis of the jaw, osteonecrosis, bisphosphonates, dentists 
B ifosfonatlar, endojen pirofosfonatların metabolize olmayan analogları olup, osteoklastik fonksiyonu inhibe eden ilaçlardır (1).

Bifosfonatlar kandaki ortalama ömürleri 30 dakika - 2 saat gibi kısa bir süre olmasına rağmen kemikte ortalama 10 yıl bozulmadan kalabilirler. Bifosfonatlar, hidroksiapatit kristallerine rahatlıkla bağlanırlar, bu bölgelerden salınırlar ve osteoklastlar tarafından absorbe edilirler. Bifosfonat ilaçlar, osteoklastların hücre içinde kolesterol üreten enzimlerinden biri olan farnesildifosfatın sentezini inhibe ederler. Böylece osteoklastın kemik rezorbsiyonunu oluşturabilmesi için gereken yüzey özellikleri oluşamaz ve osteoklastik aktivite inhibe edilmiş olur. Bifosfonatlar olgunlaşmış osteoklastlara, olgunlaşmamış ve öncü osteoklast hücrelerine de etki gösterebilirler. Bundan dolayı da kemikte rezorpsiyona ve rejenerasyon miktarında azalmaya neden olurlar. Bifosfonatların osteoblastlar üzerindeki etkileri osteoklastlar üzerindeki etkileri kadar iyi ve net açıklanamamiştır (2).

Bifosfonat ilaçlar daha çok; postmenapozal dönemde kadınlarda kemik mineral yoğunluğunu artırdığı ve osteoporoza bağlı oluşan kemik kırıklarını azalttığı için, malign tümörlerle ilişkili hiperkalsemi tedavisinde, Paget's hastalığı, fibröz displazi, heteretropik osifikasyonlar, ankilozan spondilit gibi kemikle ilişkili hastalıkların tedavisinde, anti-tümöral etkisinden dolayı göğüs, prostat ve akciğer gibi kemiğe metastaz olası olan kanserlerin tedavisinde, Multiple myleoma'da iskeletsel komplikasyonları önleme amacıyla, Osteogenezis imperfektalı bireylerde kemik frajilitesini azaltmak amacıyla ve Gaucher Sendromda kemik lezyonlarının tedavisi amacıyla kullanılmaktadır (2-6)

Bifosfonat türü ilaç kulllanımına bağlı olarak gelişen çene kemikleri osteonekrozları (BRONJ) ilk olarak 2003 yılında Marx ve arkadaşları tarafından yayınlanmıştır. 2009 yılında The American Association of Oral and Maxillofacial Surgeons (AAOMS) yayınladığı rapora kadar bifosfonat osteonekrozu ile ilgili kabul edilmiş evrensel bir tanımlama yapılmamıştır (2). 2014 yılında ise yalnızca bisfosfonatIarın değil, yeni nesil kemoterapi ilaçlarının da aynı etkiyi göstermelerinden dolayı durum güncellemesi gerekliliği ortaya çıkmıştır. AAOMS, bisfosfanata bağlı çene osteonekrozu (BRONJ) terimi yerine; ilaca bağlı çene kemiği osteonekrozu (MRONJ) teriminin kullanılmasını önermiştir. Bu değişim; antirezorptif ve antianjiogenik ilaç tedavisiyle ilişkili maksilla ve mandibulayı içeren osteonekroz olgularının artan sayısı ile desteklenmektedir (4).
İlaç kullanımına bağlı gelişen çene osteonekrozu, ilacın tüketim süresine, dozuna, uygulanma yoluna (oral /intravenöz), ilacın nitrojen içerip içermediğine, hastanın sistemik durumuna, hastanın oral hijyenine, yapılan dental girişimlere göre farklı zamanlarda ve farklı boyutlarda ortaya çıkar $(4,7)$. Bu tip ostoenekrozlar, mandibulanın daha kompakt kemik yapısına sahip olması nedeniyle mandibulada maksillaya oranla daha fazla görülmektedir. Bu osteonekroz vakaların çoğunlukla uygulanan oral cerrahi işlemler ya da diş çekimleri sonrasında oluşabildiği gibi, \%40 oranında spontan olarak oluşabildiği de bildirilmektedir. Spontan olarak gelişen osteonekroz vakalarında prognoz daha kötüdür (8).

Osteonekrozun klinik bulgularında spontan ya da provoke ağrı, dişlerde mobilite, mukozada şişlik, eritem ve ülserasyon, ilgili bölgede parestezi ve anestezi, nekrotik grimsi sarı renkte, düzensiz ekspoze kemik yüzeyi, akut abse, osteomyelit, sekestr oluşumu, trismus, halitozis, deride fistül, Aktinomiçes enfeksiyonu, lenfoadenopati, maksiler sinüzit veya oroantral fistül, mandibulada patolojik fraktür gibi spesifik olmayan birçok bulgu olabilir. Osteonekrozun radyolojik bulgularında ise kemik yıkım alanları bulunmaktadır. Ayrıca spesifik özellikleri nekrotik kemiğin, radyoopak sekestr ile beraber yoğun trabekül ve düzensiz radyolüsent alanların varlığıdır (9).

2014 yılında güncellenen MRONJ için tedavi gereksinimleri, AAOMS tarafından belirlenmiştir. MRONJ tedavisinde uygulanan yöntemler ise; konservatif tedavi, yüzeyel debridman ve debridmandır (4).

Bu çalışmada amaç kamuya bağlı bir Ağız ve Diş Sağlığı Merkezi'nde çalışan diş hekimlerinin antirezorptif ilaçlar ve etki mekanizmaları, ilaca bağlı olarak çenelerde oluşan kemik osteonekrozu hakkında bilgi ve farkındalıklarının değerlendirilmesi amaçlanmıştır.

\section{Gereç ve yöntemler}

Bu çalışma, bir ilde bulunan Ağız ve Diş Sağlığı Merkezi'nde çalışan yaşları 26-55 arasında olan toplam 35 (16 kadın ve 19 erkek) diş hekiminin değerlendirilmesiyle gerçekleştirildi. Araştırmaya etik kurul onayı alındıktan sonra başlandı. Bu çalışma Helsinki İnsan Hakları Bildirisi ile ilgili kılavuz ilkelere uygun olarak yürütülmüştür. Çalışmaya katılan diş hekimlerine gerekli bilgilendirmeler yapıldıktan sonra 'Gönüllü Bilgilendirilmiş Onam Formu' alındı. Katılımcıların araştırmaya dahil edilmesinde sadece Ağız ve Diş Sağlığı Merkezinde çalışan diş hekimi olma şartına bakıldı. Katılımcılardan; sosyo-demografik ve bifosfonat ilaçlar, ilaca bağlı oluşan kemik osteonekrozu ve tedavisi, 
kemik osteonekrozu yapan ilaçlar ve etki mekanizması, osteonekroz vaka tanımı ve tedavisini içeren konular hakkında sorular içeren 20 soruluk anketi doldurmaları istendi $(n=35)$. Anket formunda bulunan soruların \%60'ına evet cevabı veren, ilaçlar, ilaçların mekanizması, atılımı, çenelerde oluşan osteonekroz ve tedavisi hakkında bilgi sahibi olduğunu belirten ve açıklamasını yapan ayrıca bu bilgileri nerlerden öğrendiğini detaylı bir şekilde bildiren diş hekimleri ilaca bağlı gelişen kemik osteonekrozu ve tedavisi, bifosfonat ilaçlar konuları hakkında farkındalığı ve bilgisi var olarak kabul edildi.

\section{Bulgular}

Araştırmaya dahil edilen bireylerin yaş ortalaması 36,54 olarak bulunmuştur. Bireylerin 19'u $(\% 54,2)$ erkek, 16 'sı $(\% 45,8)$ kadındır. Daha önce özel sektörde çalışan diş hekimi sayısı 30'dur $(\% 85,7)$. Bunların 14'ü $(\% 46,6)$ erkek iken 16 'sı $(\% 53,4)$ kadındır. Araştırmaya dahil edilen toplam 35 hekimin sadece 19'u (\%54) aktif olarak diş hekimliği ile ilgili kongre ve dergileri takip etmektedir. Bunlardan 12'si (\%63) kadın, 7'si (\%37) erkek hekimlerdir (Tablo 1).

Tablo 1. Daha önce özel sektörde iş tecrübesi olan ve diş hekimliği ile ilgili kongre ve dergilerini takip eden hekim sayıları

\begin{tabular}{lccc} 
& $\begin{array}{c}\text { Kadın sayısı ve } \\
\text { yüzdesi }\end{array}$ & $\begin{array}{c}\text { Erkek sayısı ve } \\
\text { yüzdesi }\end{array}$ & Toplam \\
\hline Hekim sayısı & $16(\% 45,8)$ & $19(54,2)$ & 35 \\
$\begin{array}{l}\text { Daha önce özel sektörde } \\
\text { çalışmış hekim }\end{array}$ & $16(\% 53,4)$ & $14(\% 46,6)$ & $30(\% 85,7)$ \\
$\begin{array}{l}\text { Diş hekimliği kongre ve } \\
\text { dergilerini takip eden } \\
\text { hekim }\end{array}$ & $12(\% 63)$ & $7(\% 37)$ & $19(\% 54)$ \\
& & &
\end{tabular}

İlaca bağlı oluşan kemik osteonekrozu ve tedavisi, antirezorptif ilaçlar hakkında bilgi ve farkındalık oranı ise \%42,9 olarak bulunmuştur. Toplam 35 hekimin 15 tanesi anket sorularının \%60'ına evet cevabı vererek, gerekli açıklamalarda bulunmuşlardır. Bu 15 hekimin 9'u (\%60) kadın, 6'sı (\%40) ise erkektir. İlaca bağlı oluşan kemik osteonekrozu ve tedavisi, antirezorptif ilaçlar hakkında bilgi ve farkındalığa sahip 9 kadın hekimin 9'u (\%100), 6 erkek hekimin 5'i $(\% 83,3)$ toplamda 15 hekimin 14 'ü $(\% 93,4)$ diş hekimliği ile ilgili dergi ve kongreleri aktif olarak takip etmekte ve katılmaktadır. Diş hekimliği ile ilgili kongrelere aktif olarak katılan ve ilgili dergileri düzenli takip eden, ilaca bağlı oluşan kemik osteonekrozu ve tedavisi, antirezorptif ilaçlar hakkında bilgi ve farkındalığa sahip olan kadın ve erkek hekim sayısı arasında istatistiksel olarak anlamlı bir fark bulunmamıştır $(p>0,05)$. Illaca bağlı oluşan kemik osteonekrozu ve tedavisi, antirezorptif ilaçlar hakkında bilgi ve farkındalığa sahip 9 kadın hekimin 7'si (\%77,7), 6 erkek hekimin ise $5^{\prime i}(\% 83,3)$ toplamda 15 hekimin 12'si (\%80) daha önce özel sektörde iş tecrübesine sahiptir (Tablo 2). Illaca bağlı oluşan kemik osteonekrozu ve tedavisi, antirezorptif ilaçlar hakkında bilgi ve farkındalığa sahip, daha önce özel sektörde iş tecrübesine sahip hekimlerin erkek ve kadın sayısı yönünden değerlendirilmesinde istatistiksel olarak anlamlı bir fark bulunamamıştır ( $p>0,05$ ) (Tablo 2 ).

Tablo 2. İlaca bağlı oluşan kemik osteonekrozu-tedavisi, antirezorptif ilaçlar hakkında bilgi ve farkındalığa sahip hekimlerden özel sektör iş tecrübesi yaşayanlar ve dergi ve kongreleri aktif olarak takip edenler

\begin{tabular}{lcc} 
& $\begin{array}{c}\text { Diş hekimliği ile ilgili } \\
\text { kongre ve dergileri takip eden } \\
\text { hekim sayısı }\end{array}$ & $\begin{array}{c}\text { Özel sektörde } \\
\text { iş tecrübesi olan hekim } \\
\text { sayısı }\end{array}$ \\
\hline Kadın & $9(\% 100)$ & $7(\% 77,7)$ \\
Erkek & $5(\% 83,3)$ & $5(\% 83,3)$ \\
Toplam & 14 & 12
\end{tabular}

Illaca bağlı oluşan kemik osteonekrozu ve tedavisi, antirezorptif ilaçlar hakkında bilgi ve farkındalığa sahip 9 kadın hekimin 3'ü $(\% 33,3)$ bu konu hakkındaki bilgilerini makalelerden, 3'ü $(\% 33,3)$ makaleler ve kongrelerden, 1'i $(\% 11,1)$ makaleler ve meslektaş bilgilendirmesinden, $1^{\prime} \mathrm{i}$ $(\% 11,1)$ dergilerden, $1^{\prime} \mathrm{i}(\% 11,1)$ ise dergilerden ve meslektaş bilgilendirmesinden edindiğini belirtmiştir. 6 erkek hekimin ise 2'si $(\% 33,3)$ bu konu hakkındaki bilgilerini makalelerden, 2'si $(\% 33,3)$ makaleler, kongreler ve dergilerden, 1'i $(\% 16,7)$ kongrelerden, 1 'i ise meslektaş bilgilendirmesinden ve dergilerden edindiğini belirtmiştir (Tablo 3).

\section{Tablo 3. Faydalanılan bilgi kaynakları ve kadın-erkek hekim sayıları}

\begin{tabular}{lcc} 
Bilgi kaynakları & $\begin{array}{c}\text { Kadın Sayısı ve } \\
\text { Yüzdesi }\end{array}$ & $\begin{array}{c}\text { Erkek Sayısı ve } \\
\text { Yüzdesi }\end{array}$ \\
\hline Makaleler & $3(\% 33,3)$ & $2(\% 33,3)$ \\
Makale ve kongreler & $3(\% 33,3)$ & - \\
Makale ve meslektaş bilgilendirmesi & $1(\% 11,1)$ & - \\
Dergiler & $1(\% 11,1)$ & - \\
Meslektaş bilgilendirmesi ve dergiler & $1(\% 11,1)$ & $1(\% 16,7)$ \\
Makaleler, kongreler, dergiler & - & $2(\% 33,3)$ \\
Kongreler & - & $1(\% 16,7)$ \\
Toplam & 9 & 6
\end{tabular}

Elde edilen verilerin istatistik analizi için Ki-Kare testi, frekans/oran dağııımları kullanılmıştır. Bütün istatistik analizler için Minitab ve Microsoft Excel programlarından yararlanılmıştır. İstatistiksel anlamlılık için $p$ değeri $<0,05$ olarak kabul edilmiştir. 


\section{Tartışma}

Antirezorptif türü ilaçların yan etkileri, kemik yapım ve yıkım hızının fazla olması, travmalara ve enfeksiyona açık olması sebebiyle en çok çene kemiklerinde görülmektedirler. Diş hekimlerini ilgilendiren en önemli yan etkisi ilaca bağlı olarak oluşan çene kemiği osteonekrozudur $(10,11)$. Diş hekimlerinin bu komplikasyondan haberdar olmaları son derece önemlidir. Bizim çalışmamızda da ilaca bağlı oluşan kemik osteonekrozu hakkında diş hekimlerinin bilgi ve farkındalıkları araştırılmıştır.

Çene kemiğinde ilaca bağlı oluşan osteonekroz tanısı koyulan olguların \%68,8 'inde daha önceden diş hekimliği rutininde sıklıkla uygulanan diş çekimi ya da dental implant yerleştirilmesi gibi invaziv cerrahi işlemler yapıldığı saptanmıştır. Diş hekimlerinin antirezorptif ilaç kullanımı hakkında bilgili olmaları, anamnez alırken bu ilaçların kullanılıp kullanılmadığını sorgulamaları ve ilaca bağlı oluşan çene kemik osteonekrozları hakkında teorik ve pratik alt yapıya sahip olmaları bu komplikasyonları önlemede önemli derecede etkilidir (10-12)

Antirezorptif ilaç kullanan hastaların \%20,7-25,2'sinde kemiğin kendiliğinden açığa çıktığı, \%37,8'inde diş çekimi, \%28,2'sinde periodontal cerrahi, \%11,2'sinde dental implant yerleştirilmesi, \%0,8'inde ise kök kanalı cerrahisi gibi operatif işlemler sonrası oluştuğu bildirilmiştir (12). Bu tür ilaçları kullanan hastalarda diş hekimi yaklaşımında oldukça tedbirli, bilgili ve tecrübeli olmalıdır. Diş hekimleri bu tip ilaçların etki mekanizmaları, kullanım alanları ve uygulama yolları, komplikasyonları ve yan etkileri hakkında kendilerini geliştirmelilerdir. Bu amaçla; bizim çalışmamızda da diş hekimlerinin antirezorptif türü ilaçlar hakkında ve ilaca bağlı gelişen çene kemikleri osteonekrozu hakkında bilgi ve farkındalık seviyeleri değerlendirilmiştir.

Antirezorptif ilaç kullanan bireylerde protez kullanımı, periodontal hastalık gibi enflamatuar diş-dişeti hastalığı varIığı, apse ve kötü ağız hijyeni osteonekroz için risk faktörü olarak belirtilmektedir (13). Diş hekimleri bu tip hastalarda bu risk faktörlerini iyi bilmeli ve iyi tayin edebilmelidir. Bu sebepten dolayı diş hekimleri bu ilaçlar ve meydana getirdikleri osteonekroz olguları hakkında bilgilendirilmeli ve eğitime tabi tutulmalıdırlar. Bizde çalışmamızda bir Ağız ve Diş Sağlığı Merkezi'nde çalışan diş hekimlerinin ilaca bağlı oluşan çene kemik osteonekrozları ve tedavisi, antirezorptif ilaçların etki mekanizmaları, uygulama yoları, dozları hakkındaki bilgi düzeylerini ve farkındalıklarını değerlendirdik.
Antirezorptif ilaçlara bağlı nekrozdan korunmak amacıyla, tedaviye başlamadan önce hastalar diş hekimine yönlendirilmelidir. Hasta detaylı bir radyolojik ve klinik muayeneden geçirildikten sonra radikal karar verilmeli, tüm enfeksiyon odakları ağız ortamından uzaklaştırılmalı ve tüm cerrahi invaziv dental işlemler bitirilmelidir. Oral hijyen optimal sağlıklı duruma gelene kadar tedaviye başlanmamalıdır. Diş hekimi ve doktoru bu konular hakkında bilgili olmalı ve birbirleriyle sürekli iletişimde halinde olmalıdırlar (3). Kongre katılımları, akademik dergilerin ve makalelerin takibi; yenilikleri takip etmek, tecrübeleri paylaşmak, yeni bilgiler edinmek ve geliş̧melerden haberdar olabilmek için son derece önemlidir (14). Bizim çalışmamızda da antirezorptif ilaçlar ve bu ilaçlara bağlı olarak gelişen çene osteonekrozları hakkında bilgi ve farkındalık sahibi olan hekimlerin çoğunun diş hekimliği ile ilgili dergi ve makaleleri etkin bir şekilde takip ettikleri ve kongrelere katılımları yaptıkları ve bu komplikasyonlar hakkındaki bilgileri buralardan edindikleri belirtilmiştir.

Zineldin, sağlık sektörünün rekabet edebilirliğini koruyabilmesi için yeni tedavi yöntemlerini ve teknolojilerini yakından takip edilmesinin önemli olduğunu vurgulamaktadır. Sağlık sektöründe sunulan hizmetin kalitesinin rekabet üstünlüğü elde etmede kritik öneme sahip olduğu açıktır. Bu sebeple de kamu ve özel sağlık kuruluşları tarafından kalitenin anlaşılması, ölçülmesi ve geliştirilmesi gerekmektedir. Bizim çalışmamızda da, antirezorptif ilaçlar ve etki mekanizmaları, ilaca bağlı gelişen osteonekroz olgularından bilgi ve farkındalık sahibi olan hekimlerin özel sektör iş geçmişi olduğu tespit edilmiştir (15).

\section{Sonuç}

Sonuç olarak, birçok kemik rahatsızlıklarında ve kanser vakalarında sıklıkla kullanılan antirezorptif ilaçlar çene kemiklerinde osteonekroza sebep olabileceğinden diş hekimlerinin bu ilaçların kullanım alanları, uygulama yolları, etki mekanizmaları, çenelerde oluşturduğu osteonekrozun semptomları ve tedavisi hakkında bilgi sahibi olmaları ve tedavi gören veya görecek olan hastaları da konu hakkında bilgilendirmeleri gerekmektedir. Bu çalışmada, Ağız ve Diş Sağlığı Merkezi'nde çalışan diş hekimlerinin antirezorptif ilaçlar ve etki mekanizmaları, bu ilaçların neden oldukları çene osteonekrozları ve tedavileri hakkında bilgi ve farkındalık seviyelerinin düşük olduğu ortaya koyulmuştur. Daha kapsamlı ve daha geniş kitleleri içine alacak çalışmalara intiyaç duyulmaktadır. Ayrıca bu ilaçlar ve olası komplikasyonlar hakkında diş hekimlerine eğitici seminerler verilmesinin uygun olacağı düşünülmektedir. 


\section{Kaynaklar}

1. Migliorati CA, Woo SB, Hewson I, Barasch A, Elting LS, Spijkervet FK, Brennan MT. A systematic review of bisphosphonate osteonecrosis (bon) in cancer. Support Care Cancer 2010;18:1099-106. [CrossRef]

2. Soydan SS, Veziroğlu Şenel F, Araz K. Bifosfonata Bağlı Olarak Çene Kemiklerinde Gelişen Osteonekrozun Patogenezi ve Tedavisi. Hacettepe Diş Hekimliği Fakültesi Dergisi 2009;33:618. Erişim: http://www.dishekdergi.hacettepe.edu.tr/htdergi/ makaleler/2009sayi3makale8.pdf

3. Ruggiero S, Dodson TB, Assael LA, Landesberg R, Marx RE, Mehrotra B. American Association of Oral and Maxillofacial Surgeons Position Paper on Bisphosphonate-Related Osteonecrosis of the Jaw. Aust Endod J 2009;35:119-30. [CrossRef]

4. Ruggiero SL, Dodson TB, Fantasia J, Goodday R, Aghaloo T, Mehrotra B, O'Ryan F. American Association of Oral and Maxillofacial MRONJ derleme Tayfun Yazıcı ve ark. Surgeons on Medication-Related Osteonecrosis of the Jaw- 2014 Update. J Oral Maxillofac Surg 2014;72:1938-56. [CrossRef]

5. Suresh E, Pazianas M, Abrahamsen B. Safety issues with bisphosphonate therapy for osteoporosis. Rheumatology (Oxford) 2014;53:19-31. [CrossRef]

6. Rizzoli R. Bisphosphonates for postmenopausal osteoporosis: Are they all the same? QJM 2011;104:281-300. [CrossRef]

7. Woo SB, Hellstein JW, Kalmar JR. Narrative [corrected] review: bisphosphonates and osteonecrosis of the jaws. Ann Intern Med 2006;144:753-61. [CrossRef]

8. Scoletta M, Arduino PG, Dalmasso P, Broccoletti R, Mozzati M. Treatment outcomes in patients with bisphosphonate-related osteonecrosis of the jaws: a prospective study. Oral Surg Oral Med Oral Radiol Endod 2010;110:46-53. [CrossRef]
9. Sharma D, Ivanovski S, Slevin M, Hamlet S, Pop TS, Brinzaniuc K, et al. Bisphosphonate-related osteonecrosis of jaw (BRONJ): diagnostic criteria and possible pathogenic mechanisms of an unexpected anti-angiogenic side effect. Vasc Cell 2013;5:5. [CrossRef]

10. Hoff $A O$, Toth BB, Altundag $K$, Johnson MM, Warneke $C L$, Hu M, et al. Frequency and risk factors associated with osteonecrosis of the jaw in cancer patients treated with intravenous bisphosphonates. J Bone Miner Res 2008;23:826-36. [CrossRef]

11. King $A E$, Umland $E M$. Osteonecrosis of the jaw in patients receiving intravenous or oral bisphosphonates. Pharmacotherapy 2008;28:667-77. [CrossRef]

12. Marx RE, Sawatari Y, Fortin M, Broumand V. Bisphosphonate-induced exposed bone (osteonecrosis/osteopetrosis) of the jaws: risk factors, recognition, prevention, and treatment. J Oral Maxillofac Surg 2005;63:1567-75. [CrossRef]

13. Soğur E, Önem E, Baksı BG. Bisfosfanat kullanımına bağlı çene kemiğinde gelişen osteonekroz: Etyoloji, risk faktörleri, tanı kriterleri ve tedavi alternatifleri. Atatürk Üniv Diş Hek Fak Derg 2012;22:83-95.

14. Eke HN. An Empirical Study of the Impact of NLA Conference Attendance on Librarians' Professional Development. PNLA Quarterly 2011;75:26-37.

15. Zineldin M. The Quality of Health Care And Patient Satisfaction: an Exploratory Investigation of the 5Qs Model at Some Egyptian and Jordanian Medical Clinics. Int J Health Care Qual Assur Inc Leadersh Health Serv 2006;19:60-92. [CrossRef] 